\section{Reactivation of Hepatitis B Virus After Steroid Treatment in Rheumatic Diseases}

\section{To the Editor:}

Hepatitis B virus (HBV) infection is a global problem and is particularly endemic in some regions of the world. More than one-third of the world's population has been infected with the HBV and there are 350 million people with chronic infection; $75 \%$ of them live in Southeast Asia and the Western Pacific regions ${ }^{1,2}$. There is a chance of reactivation of a previous HBV infection in patients undergoing chemotherapy or immunosuppressive therapy for rheumatism, malignancies, autoimmune hepatitis, and systemic lupus erythematosus (SLE); this reactivation is a major cause of morbidity and mortality ${ }^{3}$. Reactivation of HBV was first described by Wands, et al, who in 1975 reported the condition in 20 patients with lymphoproliferative and myeloproliferative disorders ${ }^{4,5}$. Induced immunosuppression allows a rapid increase in viral replications and antigen expression. Restoration of immune function causes rapid, $\mathrm{T}$ cell-mediated destruction of HBV-infected hepatocytes that manifests clinically as asymptomatic self-limiting anicteric hepatitis to severe hepatitis, potentially fatal progressive decompensated hepatitis, and even death ${ }^{6}$.

In routine clinical practice, it is common to come across patients with rheumatic diseases who have HBsAg-positive serology ("overt" carriers). It is estimated that $21 \%-67 \%$ are affected (mean 50\%), with a mean mortality rate of $20 \%{ }^{6,7,8}$. However, clinical events can also develop in "occult" carriers, i.e., patients who are HBsAg-negative but positive for other markers of prior exposure to the virus, including $\mathrm{HBcAb}$ alone or in combination with HBsAb. Further, about $12 \%$ of anti-core-positive subjects (HBsAg-negative) experience reemergence of HBsAg (seroreversion ${ }^{6,9}$. Several risk factors have been proposed for reactivation of hepatitis B such as hematological malignancies, younger age, male sex, and high pretherapy HBV-DNA levels. Glucocorticoid is often reported to be associated with reactivation hepatitis. Serum levels of aminotransferases, bilirubin, and HBV-DNA are important for diagnosing hepatitis reactivation ${ }^{10,11}$

Hepatitis attributable to HBV reactivation is defined as HBeAg seroreversion or an absolute level of HBV-DNA that exceeds $10^{5}$ copies $/ \mathrm{ml}$ in the absence of clinical or laboratory features of acute infection with hepatitis A virus, hepatitis C virus, or other systemic infections ${ }^{2}$. Recent development of the prophylactic use of antiviral agents against HBV has made screening and monitoring of HBV status essential in patients with rheumatic diseases who are starting glucocorticoids, to ensure adequate prophylaxis and/or preemptive therapy for reactivation ${ }^{2,12}$. We describe the cases of 2 patients taking glucocorticoids for rheumatic diseases without timely prophylactic treatment of nucleoside analog against $\mathrm{HBV}$ reactivation.

The first case was a 32-year-old man with autoimmune hepatitis treated by prednisone $(60 \mathrm{mg} / \mathrm{day}$, oral administration for 7 days; $40 \mathrm{mg} /$ day, oral administration for 7 days; then $30 \mathrm{mg} /$ day, oral administration for maintenance treatment) from May 2009. Family history of hepatitis B and history of alcohol abuse were not observed. Pretreatment screening for HBV serology displayed the following pattern: hepatitis B surface antigen (HBsAg)-negative, antihepatitis B surface antibody (anti-HBs)-positive, hepatitis $\mathrm{B}$ envelope antigen ( $\mathrm{HBeAg}$ )-negative, antihepatitis $\mathrm{B}$ envelope antibody (anti-HBe)-positive, antihepatitis B core antibody (anti-HBc)-positive, and HBV-DNA not detectable by real-time detection polymerase chain reaction (RTD-PCR). Prophylactic antiviral therapy with nucleoside analogs was not given to the patient. On March 12, 2010, he was hospitalized in the Department of Infectious Diseases, the First Affiliated Hospital of Anhui Medical University, Hefei, China, because of recurrent severe yellow sclera for more than 10 months and aggravated for 1 month. After admission, he was diagnosed with acute-on-chronic liver failure and hepatic encephalopathy according to symptoms, physical signs, and auxiliary examination. The variation of HBV serology status was detected at this time; it displayed the following pattern: HBsAg-positive, anti-HBs-negative, $\mathrm{HBeAg}$-positive, anti-HBe-negative, anti-HBc-posi- tive, and detectable RTD-PCR levels of HBV-DNA $\left(2.30 \times 10^{8}\right.$ copies $\left./ \mathrm{ml}\right)$. The clinical or laboratory features of acute infection with hepatitis A virus, hepatitis $\mathrm{C}$ virus, and hepatitis $\mathrm{E}$ virus were absent. No information about HBV infection of his wife, transfusion history (including blood products), and trauma/operation history has been discovered. Further, the patient had been resting at home since he became ill. He was started on symptomatic and supportive treatment for liver dysfunction along with highly active antiretroviral therapy (lamivudine $0.1 \mathrm{~g} /$ day and adefovir $10 \mathrm{mg} / \mathrm{day}$ ); moreover, prednisone was gradually decreased to $10 \mathrm{mg} / \mathrm{day}$. On April 19, 2010 , symptoms of hepatic encephalopathy appeared, and there were physical signs of spontaneous bacterial peritonitis. Antiinfection treatment with meropenem was immediately added because family members of the patient refused abdominal puncture. Moreover, liver failure was further aggravated. On April 20, 2010, family members of the patient were hospitalized for additional treatment.

The second case was a 41-year-old man with SLE treated with prednisone $(60 \mathrm{mg} / \mathrm{day}$, oral administration, to the relief of symptoms; then 30 $\mathrm{mg} /$ day, oral administration, for maintenance treatment) from December 2009. Family history of hepatitis B was not observed; nevertheless, a history of alcohol abuse was determined. Pretreatment screening for HBV serology displayed the following pattern: HBsAg-positive, anti-HBs-negative, $\mathrm{HBeAg}$-negative, anti-HBe-positive, anti-HBc-positive, and the RTD-PCR level of HBV-DNA remained below the quantitation limit. B-ultrasound scan led to a diagnosis of liver cirrhosis. Further, HBsAg-positivity had been detected 6 years previously. Prophylactic antiviral therapy with nucleoside analogs was not given. On May 14, 2010, he was hospitalized in the Department of Infectious Diseases, First Affiliated Hospital of Anhui Medical University, because of abdominal distension, fatigue, and poor appetite for 1 month and aggravated for 10 days. $\mathrm{He}$ was diagnosed with acute-on-chronic liver failure, hepatic encephalopathy, and spontaneous bacterial peritonitis according to symptoms, physical signs, and auxiliary examination. HBV serology status was detected again, and it still displayed the following pattern: HBsAg-positive, anti-HBs-negative, HBeAg-negative, anti-HBe-positive, anti-HBc-positive; however, there were detectable RTD-PCR levels of HBV-DNA $\left(6.13 \times 10^{6} \mathrm{copies} / \mathrm{ml}\right)$. Clinical or laboratory features of acute infection with hepatitis A virus, $\mathrm{C}$ virus, and $\mathrm{E}$ virus were absent. No information was given about HBV infection of his wife, transfusion history (including blood products), and trauma/operation history. He was started on symptomatic and supportive treatment for liver dysfunction along with highly active antiretroviral therapy (lamivudine $0.1 \mathrm{~g}$ /day and adefovir 10 $\mathrm{mg} /$ day). Prednisone was gradually decreased to $20 \mathrm{mg} / \mathrm{day}$. On May 22, 2010, liver failure occurred. Thus, the patient received further treatment in the local hospital.

These 2 cases of patients with HBV reactivation involved nucleoside analogs against viruses and symptomatic, supportive treatment; nevertheless, liver failure still occurred. Communication and cooperation should be strengthened among different medical specialties. Patients who are HBsAg-positive or HBsAg-negative, and anti-HBC-positive (with or without anti-HBs-positivity), may receive treatment in the Department of Hematology because of different underlying diseases. Rheumatologists should also treat these patients. When patients are scheduled for immunosuppressive therapy for rheumatic diseases, they should simultaneously take the preventive therapy of antiviral drugs if they have chronic hepatitis or are inactive carriers, to prevent $\mathrm{HBV}$ reactivation ${ }^{3}$. If necessary, collaborative treatment with specialists in infectious diseases is in order to avoiding reactivation of the virus, which could give rise to serious liver damage and even liver failure. With regard to patients who are HBsAg-positive, even if HBV-DNA is $<1.0 \times 10^{3} \mathrm{copies} / \mathrm{ml}$ and there is normal liver function, patients should be given nucleoside analogs as prophylactic antiviral treatment and HBV-DNA should be regularly measured, as well as liver function. With an HBV-DNA level $<10^{5}$ copies $/ \mathrm{ml}$, antiviral therapy should be used for at least 6 months after immunosuppressive or chemotherapy; with an HBV-DNA level $>10^{5}$ copies/ml, antiviral therapy should be continued to the end of antiviral therapy to normal population. 
Patients who are HBsAg-negative, anti-HBc positive (with or without anti-HBs positive), and who have past HBV infection, should have periodic observation (every 1-3 months) of liver function, HBV serology, and HBV-DNA at the time of immunosuppressive treatment.

Once regular surveillance of $\mathrm{HBV}$ reactivation (detection of serum HBsAg in the reverse conversion in time) has begun, the patient should be offered antiviral treatment in time to avoid liver damage, or even liver failure, even though such cases are relatively rare.

JUN CHENG, MD; JIA-BIN LI, MD; QIU-LIN SUN, MD; XU LI, MD, Department of Infectious Diseases, First Affiliated Hospital of Anhui Medical University, 230022, Hefei, Anhui Province, China. Address correspondence to Dr. J-B. Li; E-mail: lijiabin948@vip.sohu.com Supported by the Key Projects of Medical Research Program in Anhui Province (No. 2010A010).

\section{REFERENCES}

1. Lee WM. Hepatitis B virus infection. N Engl J Med 1997;337:1733-45.

2. Pei SN, Chen CH, Lee CM, Wang MC, Ma MC, Hu TH, et al. Reactivation of hepatitis $\mathrm{B}$ virus following rituximab-based regimens: a serious complication in both $\mathrm{HBsAg-positive} \mathrm{and}$ HBsAg-negative patients. Ann Hematol 2010;89:255-62.

3. Uchiyama M, Tamai Y, Ikeda T. Entecavir as prophylaxis against hepatitis $\mathrm{B}$ virus reactivation following chemotherapy for lymphoma. Int J Infect Dis 2010;14:e265-6.

4. Yeo W, Johnson PJ. Diagnosis, prevention and management of hepatitis B virus reactivation during anticancer therapy. Hepatology 2006;43:209-20.

5. Wands JR, Chura CM, Roll FJ, Massrey WC. Serial studies of hepatitis-associated antigen and antibody in patients receiving antitumor chemotherapy for myeloproliferative and lymphoproliferative disorders. Gastroenterology 1975;68:105-12.

6. Francisci D, Falcinelli F, Schiaroli E, Capponi M, Belfiori B, Flenghi L, et al. Management of hepatitis B virus reactivation in patients with hematological malignancies treated with chemotherapy. Infection 2010;38:58-61.

7. Galbraith RM, Eddleston AL, Williams R, Zuckerman AJ. Fulminant hepatic failure in leukaemia and choriocarcinoma related to withdrawal of cytotoxic drug therapy. Lancet 1975;2:528-30.

8. Thung SN, Gerber MA, Klion F, Gilbert H. Massive hepatic necrosis after chemotherapy withdrawal in a hepatitis B virus carrier. Arch Intern Med 1985;145:1313-4.

9. Marzano A, Angelucci E, Andreone P, Brunetto M, Bruno R, Burra $\mathrm{P}$, et al. Italian Association for the Study of the Liver. Prophylaxis and treatment of hepatitis B in immunocompromised patients. Dig Liver Dis 2007;39:397-408.

10. Eren OO, Artac M, Boruban MC, Yavas O, Arslan U, Basaranoglu M. Chemotherapy-induced hepatitis B virus reactivation in $\mathrm{HBsAg}$ positive cancer patients: a single center experience. Med Oncol 2009;26:386-92.

11. Yeo W, Chan PK, Zhong S, Ho WM, Steinberg JL, Tam JS, et al. Frequency of hepatitis B virus reactivation in cancer patients undergoing cytotoxic chemotherapy: a prospective study of 626 patients with identification of risk factors. J Med Virol 2000;62:299-307.

12. Dai MS, Chao TY, Kao WY, Shyu RY, Liu TM. Delayed hepatitis $\mathrm{B}$ virus reactivation after cessation of preemptive lamivudine in lymphoma patients treated with rituximab plus CHOP. Ann Hematol 2004;83:769-74.

J Rheumatol 2011;38:1; doi:10.3899/jrheum.100692 